\title{
Repeated cycles of Clostridium-directed enzyme prodrug therapy result in sustained antitumour effects in vivo
}

\author{
J Theys ${ }^{1,8}$, O Pennington 2,8, L Dubois', G Anlezark ${ }^{6}$, T Vaughan ${ }^{6}$, A Mengesha', W Landuyt $^{3}$, J Anné4, PJ Burke ${ }^{5}$, \\ P Dûrre ${ }^{7}$, BG Wouters', NP Minton ${ }^{2,8}$ and P Lambin ${ }^{*, 1,8}$ \\ 'Department of Radiation Oncology (Maastro Lab), GROW Research Institute, University of Maastricht, UNS 50/23, PO Box 616, Maastricht 6200 MD, \\ The Netherlands; ${ }^{2}$ Institute of Infection, Immunity and Inflammation, Centre for Biomolecular Sciences, University of Nottingham, University Park, \\ Nottingham NG7 2RD, UK; ${ }^{3}$ Experimental Radiobiology/LEO, Gasthuisberg-CDG, Herestraat 49, Leuven 3000, Belgium; ${ }^{4}$ Laboratory of Bacteriology, \\ Rega Institute, KU Leuven, Minderbroedersstraat 10, Leuven 3000, Belgium; ${ }^{5}$ Enact Pharma, Porton Down Science Park, Salisbury SP4 0JG, UK; ${ }^{6}$ Centre \\ for Applied Microbiology and Research, Porton Down, Salisbury SP4 0JG, UK; ${ }^{7}$ Mikrobiologie und Biotechnologie, University Ulm, Ulm 89069, Germany
}

The unique properties of the tumour microenvironment can be exploited by using recombinant anaerobic clostridial spores as highly selective gene delivery vectors. Although several recombinant Clostridium species have been generated during the past decade, their efficacy has been limited. Our goal was to substantially improve the prospects of clostridia as a gene delivery vector. Therefore, we have assessed a series of nitroreductase (NTR) enzymes for their capacity to convert the innocuous CBI954 prodrug to its toxic derivative. Among the enzymes tested, one showed superior prodrug turnover characteristics. In addition, we established an efficient gene transfer procedure, based on conjugation, which allows for the first time genetic engineering of Clostridium strains with superior tumour colonisation properties with high success rates. This conjugation procedure was subsequently used to create a recombinant C. sporogenes overexpressing the isolated NTR enzyme. Finally, analogous to a clinical setting situation, we have tested the effect of multiple consecutive treatment cycles, with antibiotic bacterial clearance between cycles. Importantly, this regimen demonstrated that intravenously administered spores of NTR-recombinant C. sporogenes produced significant antitumour efficacy when combined with prodrug administration.

British Journal of Cancer (2006) 95, 1212 - 1219. doi:10.1038/sj.bjc.6603367 www.bjcancer.com

Published online 3 October 2006

(c) 2006 Cancer Research UK

Keywords: Clostridium; hypoxia; conjugation; nitroreductase; tumour

Tumour heterogeneity, particularly with regard to hypoxia and necrosis, can dramatically limit the effectiveness of anticancer therapies. Recent analysis has shown that even in small distant metastasis, large avascular regions are present which can constitute between 25 and $75 \%$ of the tumour mass (Dang et al, 2001). The poorly vascularised, hypoxic cells adjacent to these areas are difficult to eradicate with conventional treatments and can also negatively influence the efficacy of novel treatment strategies. In that context, the limited success of initially exciting oncolytic adenoviral vectors may be attributed to hypoxia, as the hypoxia-induced G1 arrest of cells is responsible for lack of viral replication, thereby rendering these vectors less effective for anticancer therapy (Pipiya et al, 2005; Shen and Hermiston, 2005). Similarly, retroviral vectors might also be less effective in hypoxic conditions, since upon activation of the PERK kinase under hypoxia, eIF $2 \alpha$ gets phosphorylated, leading to overall inhibition of translation (Koumenis et al, 2002). This defence mechanism against viral infection and the fact that hypoxic cells do not

*Correspondence: Dr P Lambin; E-mail: philippe.lambin@maastro.n

${ }^{8}$ These authors contributed equally to this work.

Revised 10 August 2006; accepted 10 August 2006; published online 3 October 2006 proliferate can negatively influence retroviral efficiency under hypoxic conditions. Perversely, the very existence of these hypoxic/necrotic regions may provide the solution. This is because they provide rather ideal environments for the growth and proliferation of obligate, anaerobic bacteria. Thus, while intravenously injected clostridial spores are dispersed throughout the body, only those that encounter the hypoxic environment of a solid tumour go on to germinate and multiply (Mose and Mose, 1964; Carey et al, 1967). Delivery is exquisitely selective, and has led to the suggestion that clostridia could be used as tumour-specific vectors for therapeutic gene delivery (Minton et al, 1995; Fox et al, 1996; Lemmon et al, 1997; Lambin et al, 1998).

During the past decade, several recombinant clostridial species that can express therapeutic proteins specifically in tumours have been generated (Lemmon et al, 1997; Theys et al, 2001a; Liu et al, 2002; Barbe et al, 2005). Although these reports established the feasibility of this delivery system and showed some antitumoural promise, the properties of the strains used were suboptimal, particularly with respect to tumour colonisation. So far, clostridial strains able to more effectively colonise tumours, typified by Clostridium sporogenes, have proven largely recalcitrant to DNA transfer.

Until now, the principal therapeutic proteins delivered using clostridial spores have been prodrug converting enzymes (Minton, 2003). These enzymes are characterised by their bystander effect 
and form the basis of the Clostridium directed-enzyme-prodrug therapy (CDEPT). In this context, the nitroreductase (NTR) class of enzymes are of particular interest because their small size increases the likelihood of efficient clostridial expression. Nitroreductase converts the 4-nitrogroup of the prodrug CB1954 (5-aziridinyl-2,4-dinitrobenzamide) to its 10000 -fold more toxic 4-hydroxylamine (4HX) derivative, which can be further metabolised to form a DNA-DNA crosslinking and apoptosis-inducing agent (Palmer et al, 2003). Interestingly, both proliferating and nonproliferating cells, as they are often present in tumour areas with gradients of hypoxia, are killed (Cui et al, 1999). The initially detected rat enzyme (DT-diaphorase), has been superseded by an enzyme (NTR-B) isolated from Escherichia coli B, due to its increased activity against CB 1954. However, unlike the rat enzyme, NTR-B also reduces the 2-nitrogroup to produce the relatively nontoxic 2 -hydroxylamine $(2 \mathrm{HX})$ derivative.

Our goal was to substantially improve the prospects of clostridia by several ways. Firstly, we aimed to improve the enzymatic conversion of the CB1954 prodrug by isolating a new NTR enzyme with equivalent or better kinetic parameters to NTR-B, but which produced only the 4HX derivative of CB 1954. Secondly, we sought to increase the levels of bacteria, and inherently of therapeutic protein, in the tumour. This required the development of a method that allowed efficient gene transfer to strains with enhanced tumour colonising capacities such as C. sporogenes. Finally, we intended to evaluate in a quantitative way the ability of the therapeutic protein delivered by the recombinant clostridia to convert sufficient levels of prodrug to produce in vivo antitumour efficacy. To this end, we limited the period of active prodrug conversion by the metabolically active vegetative recombinant clostridia in the tumour to a 2 -week period by administration of antibiotics. Analogous to a clinical setting situation, we used this approach to test the effect of multiple consecutive treatment cycles.

\section{MATERIALS AND METHODS}

\section{Bacteria and plasmids}

C. sporogenes NCIMB 10696 was obtained from the National Collection of Industrial and Marine Bacteria (NCIMB Ltd, Aberdeen, Scotland). The strain was grown in TYG media (30 $\mathrm{gl}^{-1}$ tryptone, $20 \mathrm{gl}^{-1}$ yeast extract powder, $1 \mathrm{gl}^{-1}$ sodium thioglycollate supplemented with $250 \mu \mathrm{g} \mathrm{ml}^{-1} \mathrm{D}$-cycloserine (to select for C. sporogenes)) at $37^{\circ} \mathrm{C}$ in an MkIII anaerobic workstation (Don Whitley, Shipley, UK) with $80 \% \mathrm{~N}_{2}, 10 \% \mathrm{H}_{2}$,

Table I Plasmids used in this study

\begin{tabular}{lll}
\hline Plasmid & Features & Reference \\
\hline PMTL20E & Source of ermB & (Oultram et al, 1988) \\
PMTL4 & Shuttle vector backbone & (Chambers et al, 1988) \\
PET2Ib & Expression vector & Novagen \\
PIMPI & plMI3 replicon & (Mermelstein et al, 1992) \\
PMTL634laLS2 & Clostridial expression & (Carter et al, 2005) \\
& cartridge & \\
PMTL20 & Cloning vector and & \\
& source of LacZ $\alpha$ & (Williams et al, 1990) \\
PMTL30 & Source of OriT & Invitrogen \\
PCR2.I-TOPO & TA PCR cloning vector & Invitrogen \\
PCR-Blunt II-TOPO & Blunt PCR cloning vector & Entelechon GmBH \\
PCR4-TOPO::fac2 & Source of fac2 promoter & This study \\
PMTL4-Em & Vector backbone - ColEl & \\
& Gram-negative replicon+ermB & This study \\
PMTL552 & PMTL4E+plMI3 replicon & This study \\
PMTL553 & PMTL552+expression cartridge & This study \\
PMTL554 & PMTL553+OriT & This study \\
PEOriT & OriT from pMTL30 & This study \\
PMTL555 & PMTL554+LacZalpha & \\
\hline
\end{tabular}

$10 \% \mathrm{CO}_{2}$ atmosphere. For general cloning, E. coli TOP10 (Invitrogen, Paisley, UK) was used. The host employed for expression studies was NovaBlue (DE3). Strains were grown in Luria-Bertani media at $37^{\circ} \mathrm{C}$. Media were supplemented, when applicable, with erythromycin $\left(500 \mu \mathrm{g} \mathrm{ml}^{-1}\right.$ in E. coli or $10 \mu \mathrm{g} \mathrm{ml}^{-1}$ in C. sporogenes), ampicillin $\left(100 \mu \mathrm{g} \mathrm{ml}^{-1}\right)$, tetracycline $\left(15 \mu \mathrm{g} \mathrm{ml}^{-1}\right)$ or 5 -bromo-4-chloro-3-indolyl- $\beta$-galactoside (X-Gal; $\left.40 \mu \mathrm{g} \mathrm{ml}^{-1}\right)$. Plasmids used in this study are listed in Table 1 .

\section{Isolation of NTR enzymes}

Homologues to the previously isolated (Michael et al, 1994; Anlezark et al, 2002) bacterial NTRs of E. coli (NfnB) and Bacillus amyloliquefaciens (YwrO) were identified in bacterial genomes using BLASTP. A total of $10 \mathrm{NfnB}$-like proteins and five YwrO-like proteins were selected for further study. DNA encompassing each encoding gene was amplified from the relevant genomic DNA of the target organism by PCR using appropriate oligonucleotide primers and cloned into the expression vector pET21b. In each case, the $5^{\prime}$-primer was designed so that it incorporated an $\mathrm{NdeI}$ restriction site (CATATG), whereby the ATG corresponded to the translational start codon of the gene. Each gene was inserted into pET21b at the NdeI site such that translational start codon was placed at the optimal distance from the vector encoded ribosomebinding site (RBS). To purify the enzyme, E. coli NovaBlue (DE3) cells carrying the wild-type (wt) gene were grown overnight at $37^{\circ} \mathrm{C}$ following induction with IPTG. Recombinant NTR enzymes were purified to homogeneity as previously described (Anlezark et al, 2002).

\section{NTR assays}

Quantitative assays using CB 1954 substrate were carried out at $37^{\circ} \mathrm{C}$ by HPLC as previously described (Anlezark et al, 2002). When qualitative assays were used to identify column fractions, the standard conditions were $1 \mathrm{~mm}$ prodrug, $2 \mathrm{~mm} \mathrm{NAD}(\mathrm{P}) \mathrm{H}, 4 \%$ DMSO in $100 \mathrm{~mm}$ sodium phosphate buffer $\mathrm{pH} 7,37^{\circ} \mathrm{C}$. Incubation times varied according to the enzyme activity being studied. Assays using menadione as substrate were carried out spectrophotometrically as previously described (Knox et al, 1988) using cytochrome $c$ as terminal electron acceptor. Similar procedures were used to assay flavin reductase activity with FMN and FAD as substrate and with cofactors NADH and/or NADPH. Kinetic parameters with respect to CB 1954 were determined by HPLC assay using $10 \mu \mathrm{l}$ of the final product in $500 \mu \mathrm{l}$ assay mix containing $100-1000 \mu \mathrm{M}$ CB $1954,500 \mu \mathrm{M}$ NADPH and incubating the mixture at $37^{\circ} \mathrm{C}$ for $10 \mathrm{~min}$. Reduction of CB 1954 was determined by comparison of peak areas at $325 \mathrm{~nm}$ in standard and enzyme tubes. Enzyme kinetics were only undertaken on those enzymes found in qualitative assay to produce predominantly the 4-hydroxlamine derivative.

\section{In vitro cytotoxicity of CB1954}

Microtitre plates (96 well) were obtained preseeded with V79 cells at 10000 cells ml $^{-1}$ (European Collection of Animal Cell Cultures, ECACC) in DMEM + 10\% FCS. CB 1954 was dissolved in DMSO (Sigma, Gillingham, Dorset SP84XT, UK, tissue culture grade) so that the appropriate concentrations could be dispensed by adding $5 \mu \mathrm{l}$ per well. $\mathrm{NAD}(\mathrm{P}) \mathrm{H}$ was dissolved in sterile $\mathrm{PBS}$ to give the appropriate final concentration by adding $10 \mu \mathrm{l}$ per well. Enzymes were diluted in sterile PBS. The cells were exposed for $3 \mathrm{~h}$ to $\mathrm{CB}$ 1954 or SN $23862(3.9-500 \mu \mathrm{M}$ in doubling dilutions) alone or in combination with cofactor $(\mathrm{NAD}(\mathrm{P}) \mathrm{H} 125$ or $250 \mu \mathrm{M})$ and enzyme $(4 \mu \mathrm{g})$ and subsequently left to incubate at $37^{\circ} \mathrm{C}$ and $5 \% \mathrm{CO}_{2}$ for 3-4 days. Cytotoxicity was quantified by sulphorhodamine $\mathrm{B}$ (SRB) assay. Briefly, cells were fixed by adding cold 10\% TCA for $30 \mathrm{~min}$ and washed before adding $0.4 \%$ dye in $1 \%$ acetic acid and 
incubating at room temperature for $30 \mathrm{~min}$. After washing and air drying at room temperature the dye was solubilised by adding $100 \mu \mathrm{l}$ of $10 \mathrm{~mm}$ Tris to each well. The plates were read at $492 \mathrm{~nm}$ in a Titertek plate reader. Cytotoxicity towards treated cells was expressed as $\%$ of $\mathrm{A}_{492}$ of untreated controls and statistical analysis was performed using the Mann-Whitney test. $\mathrm{ED}_{50} \mathrm{~s}$ were calculated using probit analysis.

\section{Construction of the clostridial expression vectors}

The erythromycin resistance gene (ermB) from pMTL20E was PCR amplified using the primers ermBF $\left(5^{\prime}\right.$-ATGACTGATATCACT GATGCTAGCGAAATGATACACCAATCAG- $\left.{ }^{\prime}\right)$ and ermBR $\left(5^{\prime}\right.$ CTTAGTGTTAACACAGCTGTAGGCGCTAGGGACCTC- $3^{\prime}$ ), and cloned into pMTL4 digested with EcoRV to generate pMTL4E. The Gram-positive replicon from pIMP1 was cloned between the blunt-ended BspHI sites of pMTL4E, deleting the bla gene in the process. The plasmid obtained was designated pMTL552. The expression cartridge was obtained from pMTL9341aLS2 and modified encompassing an altered ferredoxin promoter (fac2) in which the sequence preceding the ATG start codon had been replaced with AGGAGGTTAGTCAT, such that the RBS (AGGAGG) was $8 \mathrm{bp}$ away from the ATG start. The entire modified expression cartridge was then cloned into the EcoRV site of pMTL552, to give pMTL553. For conjugative mobilisation of the plasmid, a SmaI/ $E c o \mathrm{RV}$ fragment carrying the RK2 OriT region was isolated from the plasmid pEOriT and inserted into the PvuII site of pMTL553 yielding pMTL554. To enable blue/white selection for cloning purposes, LacZ alpha was cloned in pMTL554 to yield the final expression vector, pMTL555.

The most effective NTR enzyme identified was YC78_HAEIN of Haemophilus influenzae, accession Q57431, annotated as a putative $\mathrm{NAD}(\mathrm{P}) \mathrm{H}$ NTR. A synthetic gene encoding this protein was synthesised (Entelechon Gmbh, Germany), incorporating typical Clostridium codons. In parallel, the wt gene was amplified from the $H$. influenzae chromosome using the primers HinNTRF $\left(5^{\prime}\right.$-GAGGAAATCATATGACTCAAC- $\left.3^{\prime}\right)$ and HinNTRR $\left(5^{\prime}\right.$ CTGCAGGCCTTTTTTAAT- $\left.3^{\prime}\right)$. Both the wt and synthetic gene were inserted into pMTL555 between the NdeI and PstI sites to yield pOJP10 and pOJP11, respectively.

\section{Conjugation procedure}

Plasmids were introduced into C. sporogenes NCIMB 10696, M-55 and Clostridium novyi-NT (Dang et al, 2001) using a modification of the protocol previously described by Purdy et al (2002). Briefly, cells harvested from a $1 \mathrm{ml}$ overnight culture of the E. coli donor were washed in PBS before being resuspended in $200 \mu \mathrm{l}$ of an overnight culture of C. sporogenes or C. novyi-NT grown in TYG broth. The $200 \mu \mathrm{l}$ mating mix was spotted onto a TYG $+0.5 \%$ glucose $\left(\mathrm{vv}^{-1}\right)$ agar plate and incubated anaerobically for $7 \mathrm{~h}$. The mating mixture was subsequently resuspended in $500 \mu \mathrm{l}$ of sterile PBS before plating onto selective agar (TYG + erythromycin). E. coli donors were counterselected by the addition of D-cycloserine $\left(250 \mu \mathrm{g} \mathrm{ml}^{-1}\right)$ to the media. Recombinant colonies of $C$. sporogenes NCIMB 10696 were screened for the presence of the plasmid by PCR and also by retransforming the plasmid back into E. coli followed by restriction digestion verification of the plasmid.

\section{In vivo evaluation of antitumour effect}

Human colorectal carcinoma (HCT116) were injected subcutaneously $\left(1.5 \times 10^{6}\right.$ cells $)$ in the abdominal flank of female adult NMRI nu/nu mice. Tumours were measured at least twice/week in three orthogonal diameters and volumes calculated according the formula $A \times B \times C \times \pi / 6$. All experiments were conducted in accordance with local institutional guidelines, approved by the Animal Ethics Committee of the University and procedures were according to the guidelines defined by the UKCCCR (Workman et al, 1998).

When tumours reached an average volume of $400 \mathrm{~mm}^{3}$, treatment was started. Tumour colonisation was allowed $\mathrm{f}$ or 5 days before initiation of prodrug and sham treatment, while selection antibiotics (erythromycin at $60 \mathrm{mgl}^{-1}$ ) were added to the drinking water. CB1954 prodrug $\left(15 \mathrm{mg} \mathrm{kg}^{-1}\right)$ was prepared as previously described (Djeha et al, 2000) and administrated intraperitoneally (i.p.) for 5 consecutive days. Animals were subsequently treated with $200 \mathrm{mg} \mathrm{kg}^{-1}$ Flagyl $^{\mathbb{R}}$ i.p. twice daily for 9 days. During this period, the drinking water was also supplemented with Flagyl ${ }^{\circledR}$. Body weight measurements were used as a parameter for treatment toxicity. At the end of the follow-up period, or when tumours outranged the ethically allowed maximal volume, animals were killed by cervical dislocation. Tumours and normal tissues (liver, spleen) were excised, grinded and examined for colonisation levels at different time points using a procedure described previously (Lambin et al, 1998).

\section{Statistics}

All statistical analyses were performed with SPSS 12.0.1 for Windows (SPSS Inc., 2003, Chicago, IL, USA). Mixed models linear regression was used to determine the statistical significance of differences between two independent groups of variables.

\section{RESULTS}

\section{Isolation of novel NTR enzyme}

Recombinant procedures were used to produce purified protein from 10 bacterial homologues of the E. coli NfnB (NTR-B) enzyme (Michael et al, 1994) and five homologues of YwrO of $B$. amyloliquefaciens (Anlezark et al, 2002). Qualitative assays showed that only one of the YwrO-like enzymes and four of the $\mathrm{NfnB}$ homologues produced predominantly the 4HX derivative of CB1954. These enzymes were, therefore, subjected to quantitative analysis and their $K_{\mathrm{m}}$ and $k_{\text {cat }}$ with CB1954 determined (Table 2). The enzyme NTR-H isolated from $H$. influenzae (Accession no. YP_249310) possessed the most favourable properties. In addition to producing only the $4 \mathrm{HX}$ derivative from CB1954, it had a $K_{\mathrm{m}}$ and $k_{\text {cat }}$ for this substrate of $690 \mu \mathrm{M}$ and $56.2 \mathrm{~s}^{-1}$, respectively. This compares to the previously isolated bacterial enzymes of $E$. coli B (NTR-B) and B. amyloliquefaciens (YwrO) which possess a respective $K_{\mathrm{m}}$ of 862 and $618 \mu \mathrm{M}$ and a $k_{\text {cat }}$ of 6.0 and $8.2 \mathrm{~s}^{-1}$. Thus, while the affinity of NTR-H and NTR-B for the prodrug substrate $\left(K_{\mathrm{m}}\right)$ is broadly equivalent, the rate at which it is turned over $\left(k_{\text {cat }}\right)$ is an order of magnitude greater in the case of NTR-H. Moreover, the entire reaction product is the toxic $4 \mathrm{HX}$ derivative, as opposed to NTR-B where $50 \%$ of the reaction results in the nontoxic $2 \mathrm{HX}$ derivative.

The benefits of these improved properties on cytotoxicity were demonstrated in a set of experiments in which equivalent quantities of purified NTR enzyme were incubated with V79 cells

Table 2 Characteristics of purified bacterial nitroreductases

\begin{tabular}{llccr}
\hline Enzyme & Product & $\boldsymbol{K}_{\mathbf{m}}(\boldsymbol{\mu} \mathbf{M})$ & $\left.\boldsymbol{k}_{\mathbf{c a t}} \mathbf{( s}^{-\mathbf{-}}\right)$ & $\begin{array}{r}\mathbf{E D}_{\mathbf{5 0}} \mathbf{C B} \\
\mathbf{I 9 5 4}(\boldsymbol{\mu} \mathbf{M})\end{array}$ \\
\hline NfnB & $4 \mathrm{HX}+2 \mathrm{HX}$ & 682 & 6.0 & 6.3 \\
YwrO BAM & $4 \mathrm{HX}$ & 617 & 8.2 & 137.1 \\
Ydgl & $4>2 \mathrm{HX}$ & 3863.9 & 30.3 & 15.3 \\
YodC & $4>2 \mathrm{HX}$ & 552.2 & 58 & 20.3 \\
Haemophilus influenzae NfnB & $4 \mathrm{HX}$ & 690 & 56.2 & 4.7 \\
Campylobacter jejuni NfnB & $4 \mathrm{HX}$ & 217 & 6.1 & 55.8 \\
Porphyromonas gingivalis YwrO & $4 \mathrm{HX}$ & 1200 & 3.2 & 252.3 \\
\hline
\end{tabular}

4HX $=4$-hydroxylamine. 


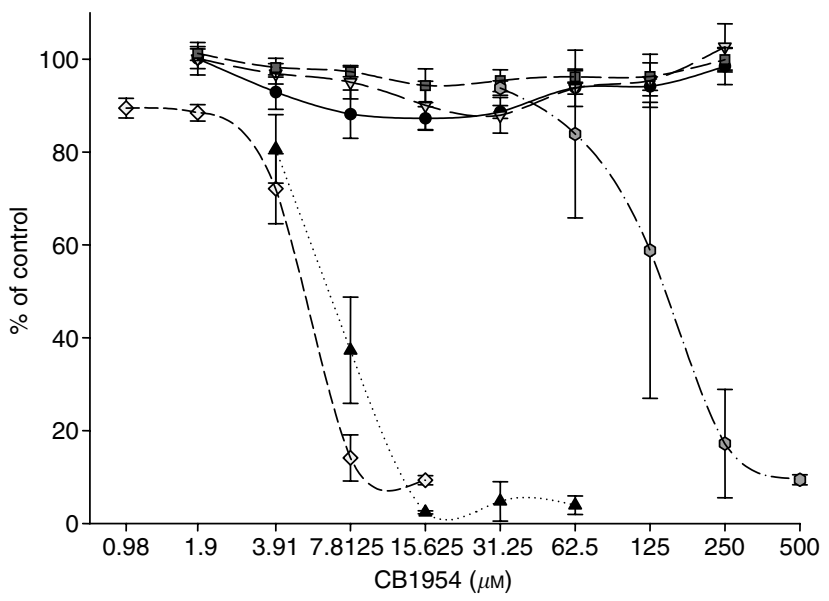

Figure I Assessment of CBI954 cytotoxicity. Cytotoxicity of CB 1954 was assessed in 96-well plates seeded with V79 cells $\left(10^{4}\right.$ per $\mathrm{ml}$ ) by incubating them with $\mathrm{CB} 1954$ alone $(3.9-500 \mu \mathrm{M})$, prodrug $+\mathrm{NAD}(\mathrm{P}) \mathrm{H}$ $(250 \mu \mathrm{M})$, or prodrug, cofactor and enzyme $\left(4 \mu \mathrm{g}\right.$ well $\left.{ }^{-1}\right)$ for $3 \mathrm{~h}$ in serum free DMEM. The medium was replaced and the cells grown for $72-96 \mathrm{~h}$ post-treatment in DMEM + 10\% FCS until control (untreated) cells had achieved confluence. The cells were fixed, stained with SRB and the plates read at $492 \mathrm{~nm}$. Results are expressed as \% of control (untreated cells). Key: - , prodrug alone; $\mathrm{O}$, prodrug $+\mathrm{NADH} ; \boldsymbol{\Delta}$, prodrug $+\mathrm{NADPH} ; \mathbf{\square}$, HinNTR + NAPDH + Prodrug; $\square, \mathrm{NfnB}+\mathrm{NADH}+$ prodrug, and; YwrO + NADPH + prodrug.

in the presence of varying concentrations of CB1954 (Figure 1). The greatest degree of killing was observed in the case of NTR-H. In general, with all the enzymes tested (Table 2), $\mathrm{ED}_{50}$ appeared to be more highly related to $k_{\text {cat }}$ as opposed to $K_{\mathrm{m}}$, with NTR-H proving to be the most potent.

\section{Transformation of Clostridum spp with superior tumour colonising properties}

Having established the superiority of the NTR-H, we sought to introduce an expression plasmid carrying the gene into the Clostridium strains with the best tumour colonising properties. A method of transforming the selected species, C. sporogenes, has previously been described (Liu et al, 2002). However, repeated attempts to obtain transformants with this method of two different C. sporogenes strains and of C. novyi-NT in our laboratories over a period of 2 years were unsuccessful. We therefore explored the use of a conjugative procedure, initially developed for the introduction of plasmids into Clostridium difficile (Purdy et al, 2002).

In our initial experiments we utilised C. sporogenes ATCC 13732 as the recipient, and we were able to show that plasmids could be consistently introduced at appreciable frequencies. The rate of transfer varied between $1.5 \times 10^{-7}$ and approaching $1.0 \times 10^{-4}$ transconjugants per recipient, dependant on the plasmid employed (Table 3). Significantly, for those plasmids tested (Table 3) this method also proved to be applicable to C. sporogenes M-55 (Mose and Mose, 1964) and C. novyi-NT (Dang et al, 2001; Bettegowda et al, 2003), which had previously proven recalcitrant to all transformation attempts. With this conjugation method, we obtained success rates of $70-90 \%$, depending on the strain being used. In all cases, the plasmid could be reisolated by transformation into E. coli, and its authenticity established through analysis of suitably restricted samples on agarose gels.

Having derived an efficient gene transfer procedure, we constructed a purpose built expression vector, pMTL555, in which two different genes encoding NTR-H were independently cloned (Figure 2). The first represented the wt gene, the second was a synthetic gene, in which the codons were changed to match the
Table 3 Transfer frequencies of various plasmids from E. coli donors into three different clostridial strains

Conjugation efficiency (transconjugants per recipient strain)

\begin{tabular}{|c|c|c|c|}
\hline Plasmid (replicon) & $\begin{array}{l}\text { C. sporogenes } \\
\text { ATCC } 13732\end{array}$ & $\begin{array}{c}\text { C. sporogenes } \\
\text { M-55 }\end{array}$ & C. novyi-NT \\
\hline $\begin{array}{l}\text { pMTL555 (pIMI3) } \\
\text { pMTL950।/pCTC4I (pAM } \beta \mid) \\
\text { pMTL940। (pCBI02) } \\
\text { PMTL96II (pIP404) } \\
\text { pMTL930। (pCD6) }\end{array}$ & $\begin{array}{l}1.44 \times 10^{-7} \\
1.18 \times 10^{-6} \\
8.86 \times 10^{-5} \\
8.3 \times 10^{-6} \\
4.00 \times 10^{-5}\end{array}$ & $\begin{array}{l}1.84 \times 10^{-7} \\
1.27 \times 10^{-6} \\
N D \\
N D \\
N D\end{array}$ & $\begin{array}{l}N D \\
1.80 \times 10^{-7} \\
N D \\
N D \\
N D\end{array}$ \\
\hline
\end{tabular}

Plasmids pMTL930I, pMTL940 I, pMTL950I and pMTL96II are described by Purdy et al (2002). Plasmid pCTC4I is described by Williams et al (1990).

Clostridium codon usage. Following the introduction of the two recombinant plasmids (pOJP10 and pOJP11, wt and synthetic NTR-H, respectively), verification of the transconjugants indicated no structural change to either pOJP10 or pOJP11. The levels of NTR in both recombinant derived samples were significantly higher compared to wt control samples. As the lysate derived from cells carrying pOJP11 produced slightly higher levels than cells harbouring pOJP10, we chose the NTR-H expressing C. sporogenes strain carrying pOJP11 to evaluate its ability to produce antitumour activity.

\section{In vivo antitumour activity following systemic administration of recombinant $C$. sporogenes}

Our aim was to determine whether the levels of NTR-H delivered by the recombinant $C$. sporogenes were sufficiently high to cause enough prodrug conversion to result in measurable antitumour efficacy. A tumour regrowth delay assay was used to quantify the magnitude of this effect. Nu/nu mice xenografted with HCT116 were injected with NTR-H expressing C. sporogenes spores when tumours reached an average volume of $400 \mathrm{~mm}^{3}$. In order to be potentially useful for the treatment of disseminated or inaccessible tumours, injections were given systemically rather than through local injection. Animals were divided into four groups that received (1) no treatment, (2) CB1954 prodrug alone $\left(15 \mathrm{mg} \mathrm{kg}^{-1}\right.$, five times a week), (3) recombinant spores (at a concentration of $5.10^{7} \mathrm{cfu}$ in a volume of $100 \mu \mathrm{l}$ saline via the tail vein) followed by prodrug vehicle only (sham treatment) or (4) recombinant spores followed by CB1954 prodrug solution, respectively. To allow tumour colonisation to take place, prodrug or sham treatment started at day 5 after spore injection. Although the in vivo feasibility of the CDEPT approach has been investigated in the past, it has been difficult to discriminate between the specific effect of prodrug conversion and the effect of the bacteria only. The main reason is the continuous presence of recombinant bacteria during the entire follow-up and consequently, their potential contribution to the observed antitumour effects. Therefore, in order to quantitatively evaluate the CDEPT approach, we eradicated the C. sporogenes form the tumour following the daily prodrug injections by an antibiotic treatment course (Flagyl ${ }^{\circledR}, 200 \mathrm{mg} \mathrm{kg}^{-1}$, $2 \times$ daily, for 9 days). This allowed us to specifically separate the effects of the recombinant bacteria alone from the effects of the bacteria in combination with the prodrug.

Tumour colonisation following recombinant spore administration but before the onset of antibiotic treatment was quantified by performing dilution series of randomly selected tumours from spore-treated animals. All tumours investigated showed colonisation levels of $10^{8}-10^{9} \mathrm{cfu} \mathrm{g}^{-1}$ tumour tissue. As expected, viable clostridia could not be detected in normal tissues. Importantly, tumour colonisation levels decreased below the detection limit 


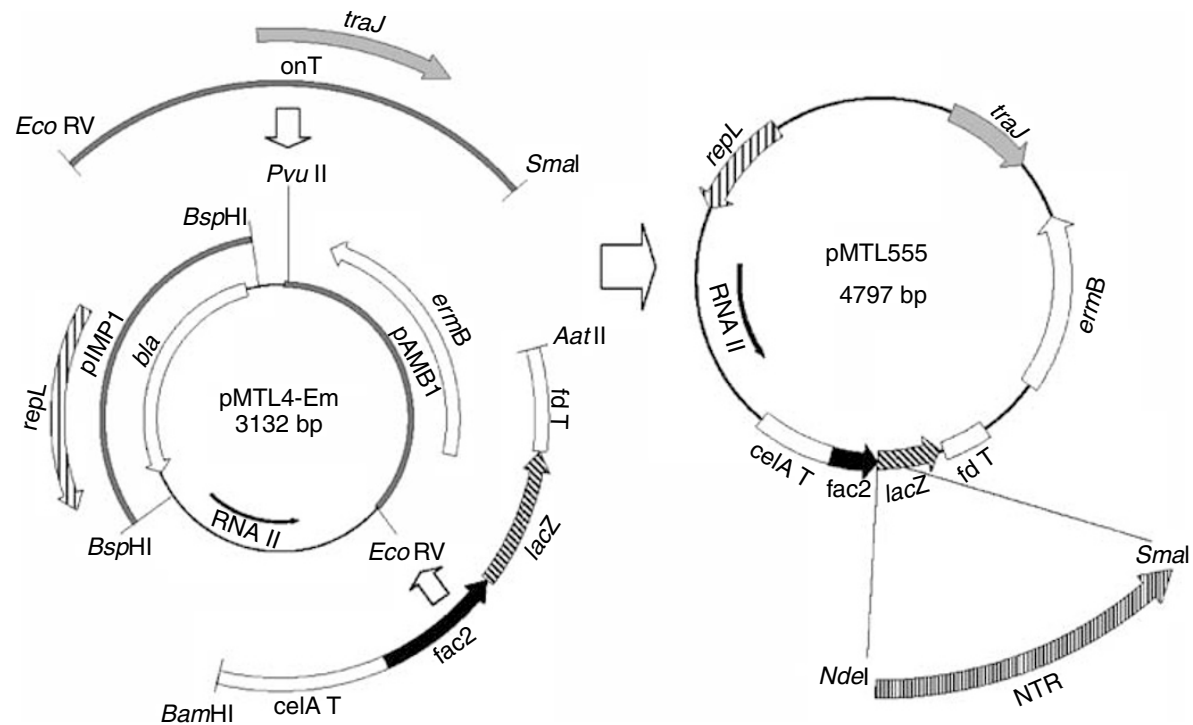

Figure 2 Construction of plasmids overexpressing NTR. The derivation of DNA fragments used to assemble the expression vector pMTL555 is as indicated. For a detailed description see Materials and Methods. Key: repL, replication protein of pIMI3, taken from the derivative plasmid pIMPI, bla, $\beta$ lactamase of pMTL4; ermB, erythromycin resistance gene from plasmid pAM $\beta$ ।; traj, transfer protein from the 'origin of transfer' (oriT) of plasmid RK2; RNAIII, replication region of CoIEI, taken from the derivative plasmid PMTL4; celA T, transcriptional terminator of the Clostridium thermocellum celA gene; fac2, the promoter of the Clostridium pasteurianum ferredoxin gene, derivatised to include an E. coli lac operator; lacZ, $\beta$-galactosidase alpha fragment; fd T, transcriptional terminator of the C. pasteurianum ferredoxin gene. Gene fragments encompassing NTR enzymes (NRase) are cloned into the lac Z region using the Ndel site adjacent to the fac2 RBS and an appropriate site (e.g., Smal) in the pMTL20 polylinker region present in lacZ.
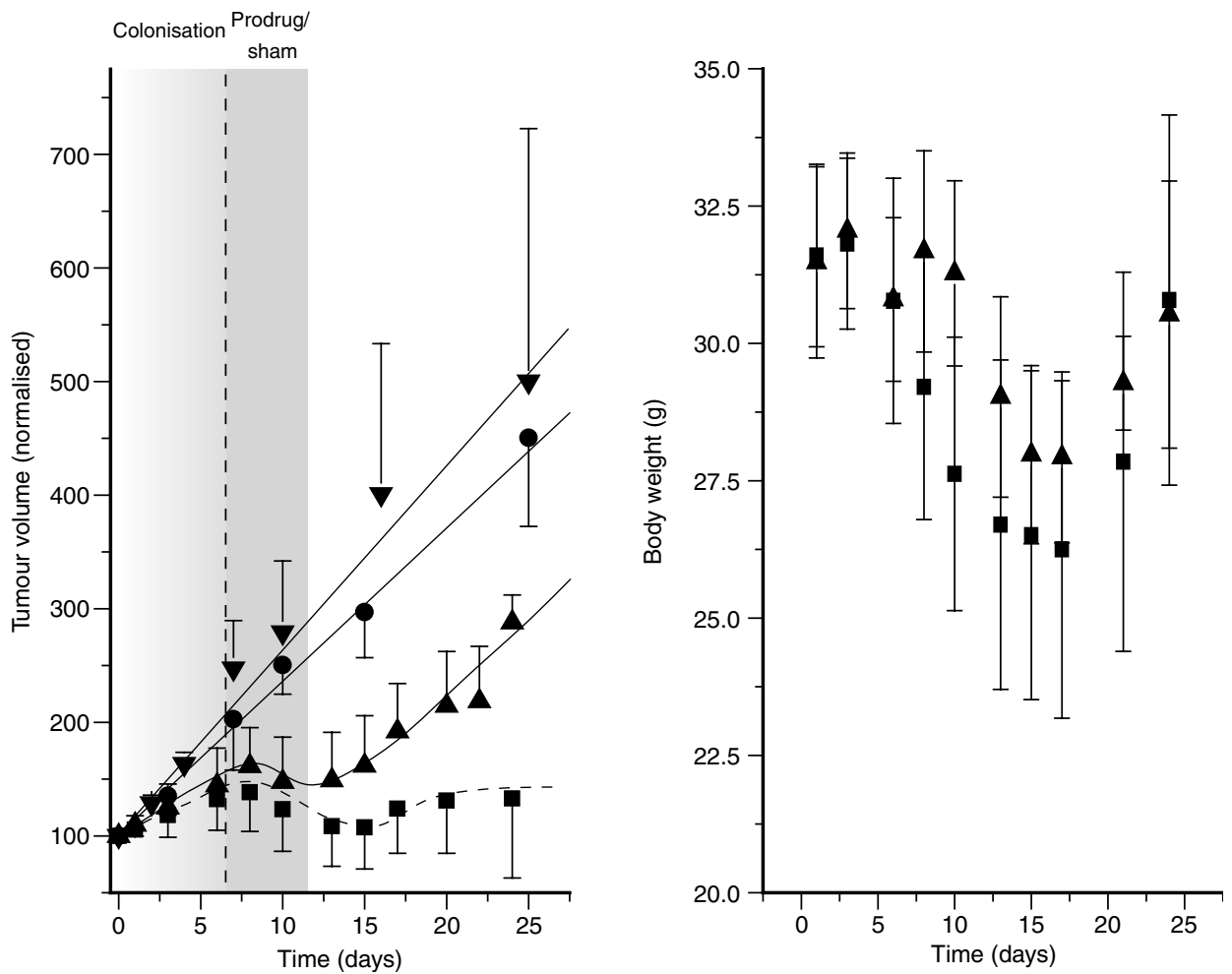

Figure 3 Antitumour effect following systemic administration of NTR-recombinant $C$. sporogenes spores to nu/nu mice bearing HCTII6 tumours. (A) Tumour growth after one cycle of recombinant C. sporogenes treatment with CBI954 prodrug ( $\mathbf{\square})$ or vehicle only (sham) (A) treatment. Control animals received no treatment $(\mathbf{O})$ or CBI954 alone $(\boldsymbol{\nabla})$. (B) Representative body weight evolution during a treatment cycle. Data are from at least five mice per group with error bars showing standard deviations for each group. Tumour volumes are normalised to 100 arbitrary units at the start of the treatment, allowing comparison of tumour growth within and across groups.

following antibiotic treatment, indicating the efficacy of the Flagyl ${ }^{\circledR}$ therapy. As already well established using other NTRdirected gene therapy approaches (Djeha et al, 2001), CB1954 administration alone had no effect on tumour volumes
(Figure 3A). Administration of spores alone caused a moderate, but significant tumour growth delay $(P<0.0001$, mixed linear regression analysis) (Figure $3 \mathrm{~A}$ ). This was a consequence of modest tumour lysis and the appearance of haemorrhagic necrosis, 
an observation also made when using other clostridial species such as C. sporogenes M55 and C. novyi-NT (Dang et al, 2001). When combined with CB1954 administration, the antitumour effect significantly increased $(P<0.0001$, mixed linear regression analysis) (Figure $3 \mathrm{~A}$ ), thereby establishing the in vivo treatment efficacy of the NTR CDEPT approach. During the treatment, animals in both treatment arms showed a transient weight loss. This effect was not significantly different between the two groups. Most importantly, the observed weight loss was totally reversible and the animals recovered completely following the antibiotic treatment (Figure 3B).

\section{In vivo efficacy of repeated CDEPT treatment cycles}

In a clinical setting, chemotherapy is typically given in multiple cycles in order to maximise its effects. Analogous to this situation, we questioned whether clostridial therapy could be given repeatedly. A treatment cycle started at the day of spore injection (day 1), followed 5 days later (day 6) by prodrug or vehicle treatment for 5 days. Each treatment cycle was then followed by antibiotic treatment during 9 days. Eventually animals were allowed to recover for an additional period of 5-7 days. Shamtreated animals were given two consecutive identical cycles. The tumour growth delay caused by each of the two (sham) treatment cycles was very similar (Figure 4). This result indicates not only that the bacteria can effectively recolonise the tumour to result in an antitumour effect, but also that the tumour microenvironment following the first treatment cycle did not fundamentally change.

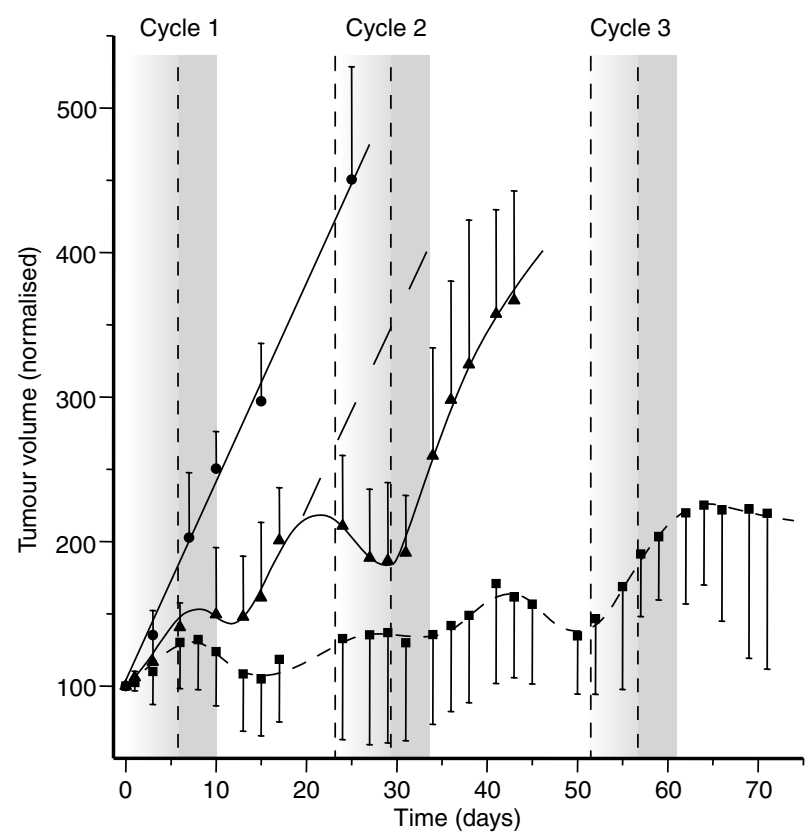

Figure 4 Antitumour effect following repeated treatment cycles of NRase-recombinant C. sporogenes in combination with CBI954 administration. Groups were recombinant C. sporogenes treatment with CBI954 prodrug $(\boldsymbol{\square})$ or vehicle only (sham) $(\boldsymbol{A})$ treatment and control animals, receiving no treatment ( ) . The dashed line indicates the expected tumour growth following one treatment cycle (based on results shown in Figure 3A). A single treatment cycle consisted of bacterial spore administration at day 0 , followed by CB1954/vehicle administration at day 6 , during 5 days. Each treatment cycle was followed by antibiotic therapy and an additional recovery period for the animals (for more details, see legend Figure 3 and text). Sham-treated animals received two treatment cycles before tumour volumes outranged the ethically allowed maximum. The CBI954 treated group was given an additional third treatment cycle. Tumour volumes are normalised to 100 arbitrary units at the start of the treatment, allowing comparison of tumour growth within and across groups.
Despite the observed growth delay within the sham-treated group, the animals in this group had to be killed for ethical reasons by the end of the second treatment cycle because their tumour volumes became too high. In contrast, and more importantly, a highly significant and much bigger antitumour effect was observed in animals that were treated twice with recombinant spores combined with CB1954 prodrug (Figure 4). This allowed application of an additional third treatment cycle. Throughout the three cycles, the treatment resulted in sustained growth delay effects.

\section{DISCUSSION}

In the current paper, we report significant progress in the use of clostridia to deliver prodrug-converting enzymes specifically to tumours. As a first step to improve the system, we isolated a novel NTR enzyme with better characteristics than NTR enzymes used so far. The NTR-H enzyme was demonstrated to be the best out of 15 tested bacterial NTR homologues. The enzyme produced only the toxic 4HX CB1954 derivative and showed the best kinetic parameters of all the enzymes tested. As expected, the superior enzyme properties translated into an enhanced toxicity profile in vitro. To evaluate the in vivo efficacy of this novel enzyme, transfer of the NTR-H enzyme to a Clostridium strain with enhanced tumour colonisation properties was absolutely necessary. Indeed, although previous CDEPT work undoubtedly established the safety and feasibility of the approach, proof of in vivo antitumour efficacy has so far been limited (Lemmon et al, 1997; Theys et al, 2001a; Liu et al, 2002). The major reason for this failure has been attributed to the low tumour colonisation efficiency of the employed strains. Until recently, the best tumour colonising strains, such as $C$. sporogenes or C. novyi-NT, could not be transformed. Thus, the reported development a few years ago of a transformation system based on electroporation for C. sporogenes, was encouraging (Liu et al, 2002). Unfortunately, the reported transformation procedure could never be reproduced in our laboratories. As exogenous endonucleases represent a major impediment to DNA transfer, we therefore devised a procedure based on conjugative transfer from $E$. coli donors. Here, we demonstrate that this procedure can be used to introduce recombinant plasmids into superior tumour colonising strains such as C. sporogenes, C. oncolyticum and C. novyi-NT at high frequencies and with high success rates. Thanks to this breakthrough, it will now be possible to express essentially any heterologous gene of interest in these clostridial vectors. As shown here for NTR-H, the adaptation of the heterologous gene codons to the codon usage in the clostridial host, characterised by its low $\mathrm{G}+\mathrm{C} \%$ content, might further increase therapeutic protein yield.

Finally, we evaluated if the recombinant $C$. sporogenes strain could deliver enough NTR-H to tumours in vivo to convert sufficient levels of prodrug to produce antitumour efficacy. Although in vivo antitumour effects using a CDEPT strategy have already been demonstrated with recombinant clostridia, it has been difficult to attribute the observed effects specifically to prodrug conversion, since the bacteria remain present in the tumour. As the bacteria have antitumour effects in their own right, as demonstrated in our work, it is not clear how much of the effect is due to their continuous presence. We therefore devised a way to quantify the magnitude of the antitumour effect due to prodrug conversion by giving pulse treatment cycles, followed by antibiotic treatment. Clearance of the bacteria from the animal not only allowed recovery after the treatment cycle, it also enabled a precise and direct quantification of the antitumour effect. In order to minimise all secondary effects that could be potentially involved in mediating the antitumour effect, we chose immunocompromised mice as a model, although there is no evidence for an immune response as shown earlier in immunocompetent rats (Theys et al, 2001b). Our results clearly demonstrate that intravenously administered spores of $C$. sporogenes expressing NTR-H produce 
significant antitumour efficacy when combined with prodrug administration. Most importantly, highly significant and prolonged antitumour efficacy could be obtained following repeated cycles. As we observe such a striking antitumour response, it must mean that not only the hypoxic but also aerobic cells are being killed as a result of an additional bystander effect. Such a phenomenon has indeed been described for NTR in combination with CB1954 (Djeha et al, 2000; Wilson et al, 2002). Therefore, the use of a prodrug activating enzyme not only is a further safeguard to the system (compared to expression of a direct cytotoxic protein which might produce host toxicity if it comes in circulation), but also provides considerable potential for treatment amplification. To our knowledge, this is the first demonstration of a sustained antitumour effect following multiple cycles of recombinant clostridia treatment. Overall, this indicates that maturation of inactive spores into vegetative rods following a first cycle does not eliminate the activity of subsequent administrations. Our data are in line with our own previously reported results (Theys et al, 2001b) and with the observations of Liu et al (2002) showing no reduction in numbers of vegetative cells $\mathrm{g}^{-1}$ tumour occurring between 7 and 14 days after a single spore injection. This is not limited to animals with an immunocompromised immune system since it was demonstrated some 25 years ago that repeated clostridial spore administration could be performed in tumourbearing rats (Gericke et al, 1979). This is likely due to the lack of immunogenicity of the applied clostridial spores. Moreover, transition from spores to the vegetative reproductive state only occurs in the severe hypoxic and necrotic region of the tumour, considered to be an immune privileged site.

Although the observed effects of the therapy were significant, additional efficacy would be predicted when combined with radiotherapy and/or conventional chemotherapy. Other potential combined treatment modalities include specific targeting of the structurally abnormal tumour blood vessels with vascular targeting agents as we (Theys et al, 2001b) and others (Dang et al, 2001) have already successfully reported. In addition, more soluble derivatives of CB1954 that cause more effective tumour regression have recently been described (Wilson et al, 2002) and since 5-FU and CB1954 have been shown to act synergistically (Palmer et al, 2003), the combinatorial use of prodrug activating enzymes (CDase and NTR) might be a promising option for CDEPT.

\section{ACKNOWLEDGEMENTS}

We thank Kim Paesmans for technical assistance. The work was financially supported by the QLK3-CT-2001-01737 grant of the European Community. Ludwig Dubois is a PhD student supported by the LSCH-CT-2003-502932/EUROXY Grant.

\section{REFERENCES}

Anlezark GM, Vaughan T, Fashola-Stone E, Michael NP, Murdoch H, Sims MA, Stubbs S, Wigley S, Minton NP (2002) Bacillus amyloliquefaciens orthologue of Bacillus subtilis ywrO encodes a nitroreductase enzyme which activates the prodrug CB 1954 Microbiology 148: 297-306

Barbe S, Van Mellaert L, Theys J, Geukens N, Lammertyn E, Lambin P, Anne J (2005) Secretory production of biologically active rat interleukin2 by Clostridium acetobutylicum DSM792 as a tool for anti-tumor treatment. FEMS Microbiol Lett 246: 67-73

Bettegowda C, Dang LH, Abrams R, Huso DL, Dillehay L, Cheong I, Agrawal N, Borzillary S, McCaffery JM, Watson EL, Lin KS, Bunz F, Baidoo K, Pomper MG, Kinzler KW, Vogelstein B, Zhou S (2003) Overcoming the hypoxic barrier to radiation therapy with anaerobic bacteria. Proc Natl Acad Sci USA 100: 15083-15088

Carey RW, Holland JF, Whang HY, Neter E, Bryant B (1967) Clostridial oncolysis in man. Eur J Cancer 3: 37-46

Carter GP, Purdy D, Williams P, Minton NP (2005) Quorum sensing in Clostridium difficile: analysis of a luxS-type signalling system. $J$ Med Microbiol 54: 119-127

Chambers SP, Prior SE, Barstow DA, Minton NP (1988) The pMTL niccloning vectors. I. Improved pUC polylinker regions to facilitate the use of sonicated DNA for nucleotide sequencing. Gene 68: 139-149

Cui W, Gusterson B, Clark AJ (1999) Nitroreductase-mediated cell ablation is very rapid and mediated by a $\mathrm{p} 53$-independent apoptotic pathway. Gene Therapy 6: $764-770$

Dang LH, Bettegowda C, Huso DL, Kinzler KW, Vogelstein B (2001) Combination bacteriolytic therapy for the treatment of experimental tumors. Proc Natl Acad Sci USA 98: 15155-15160

Djeha AH, Hulme A, Dexter MT, Mountain A, Young LS, Searle PF, Kerr DJ, Wrighton CJ (2000) Expression of Escherichia coli B nitroreductase in established human tumor xenografts in mice results in potent antitumoral and bystander effects upon systemic administration of the prodrug CB1954. Cancer Gene Ther 7: 721-731

Djeha AH, Thomson TA, Leung H, Searle PF, Young LS, Kerr DJ, Harris PA, Mountain A, Wrighton CJ (2001) Combined adenovirus-mediated nitroreductase gene delivery and CB1954 treatment: a well-tolerated therapy for established solid tumors. Mol Ther 3: 233-240

Fox ME, Lemmon MJ, Mauchline ML, Davis TO, Giaccia AJ, Minton NP, Brown JM (1996) Anaerobic bacteria as a delivery system for cancer gene therapy: in vitro activation of 5-fluorocytosine by genetically engineered clostridia. Gene Therapy 3: 173-178
Gericke D, Dietzel F, Konig W, Ruster I, Schumacher L (1979) Further progress with oncolysis due to apathogenic clostridia. Zentralbl Bakteriol [Orig A] 243: $102-112$

Knox RJ, Boland MP, Friedlos F, Coles B, Southan C, Roberts JJ (1988) The nitroreductase enzyme in Walker cells that activates 5-(aziridin-1-yl)2,4-dinitrobenzamide (CB1954) to 5-(aziridin-1-yl)-4-hydroxylamino-2nitrobenzamide is a form of $\mathrm{NAD}(\mathrm{P}) \mathrm{H}$ dehydrogenase (quinine) (EC 1.6.99.2). Biochem Pharmacol 37(24): 4671-4677

Koumenis C, Naczki C, Koritzinsky M, Rastani S, Diehl A, Sonenberg N, Koromilas A, Wouters BG (2002) Regulation of protein synthesis by hypoxia via activation of the endoplasmic reticulum kinase PERK and phosphorylation of the translation initiation factor eIF2alpha. Mol Cell Biol 22: $7405-7416$

Lambin P, Theys J, Landuyt W, Rijken P, van der Kogel A, van der Schueren E, Hodgkiss R, Fowler J, Nuyts S, de Bruijn E, Van Mellaert L, Anne J (1998) Colonisation of Clostridium in the body is restricted to hypoxic and necrotic areas of tumours. Anaerobe 4: 183-188

Lemmon MJ, van Zijl P, Fox ME, Mauchline ML, Giaccia AJ, Minton NP, Brown JM (1997) Anaerobic bacteria as a gene delivery system that is controlled by the tumor microenvironment. Gene Therapy 4: $791-796$

Liu SC, Minton NP, Giaccia AJ, Brown JM (2002) Anticancer efficacy of systemically delivered anaerobic bacteria as gene therapy vectors targeting tumor hypoxia/necrosis. Gene Therapy 9: 291-296

Mermelstein LD, Welker NE, Bennett GN, Papoutsakis ET (1992) Expression of cloned homologous fermentative genes in Clostridium acetobutylicum ATCC 824. Biotechnology (New York) 10: 190-195

Michael NP, Brehm JK, Anlezark GM, Minton NP (1994) Physical characterisation of the Escherichia coli B gene encoding nitroreductase and its over-expression in Escherichia coli K12. FEMS Microbiol Lett 124: $195-202$

Minton NP (2003) Clostridia in cancer therapy. Nat Rev Microbiol 1: 237 242

Minton NP, Mauchline ML, Lemmon MJ, Brehm JK, Fox M, Michael NP, Giaccia A, Brown JM (1995) Chemotherapeutic tumour targeting using clostridial spores. FEMS Microbiol Rev 17: 357-364

Mose JR, Mose G (1964) Oncolysis by clostridial. activity of Clostridium butyricum (M-55) and other non-pathogenic clostridia against the Ehrlich carcinoma. Cancer Res 24: 212-216

Oultram JD, Peck H, Brehm JK, Thompson DE, Swinfield TJ, Minton NP (1988) Introduction of genes for leucine biosynthesis from Clostridium 
pasteurianum into $C$. acetobutylicum by cointegrate conjugal transfer. Mol Gen Genet 214: $177-179$

Palmer DH, Milner AE, Kerr DJ, Young LS (2003) Mechanism of cell death induced by the novel enzyme-prodrug combination, nitroreductase/ CB1954, and identification of synergism with 5-fluorouracil. Br J Cancer 89: $944-950$

Pipiya T, Sauthoff H, Huang YQ, Chang B, Cheng J, Heitner S, Chen S, Rom WN, Hay JG (2005) Hypoxia reduces adenoviral replication in cancer cells by downregulation of viral protein expression. Gene Therapy 12: $911-917$

Purdy D, O'Keeffe TA, Elmore M, Herbert M, McLeod A, Bokori-Brown M, Ostrowski A, Minton NP (2002) Conjugative transfer of clostridial shuttle vectors from Escherichia coli to Clostridium difficile through circumvention of the restriction barrier. Mol Microbiol 46: 439-452

Shen BH, Hermiston TW (2005) Effect of hypoxia on Ad5 infection, transgene expression and replication. Gene Therapy 12: 902-910

Theys J, Landuyt W, Nuyts S, Van Mellaert L, Bosmans E, Rijnders A, Van Den Bogaert W, van Oosterom A, Anne J, Lambin P (2001b)
Improvement of Clostridium tumour targeting vectors evaluated in rat rhabdomyosarcomas. FEMS Immunol Med Microbiol 30: 37-41

Theys J, Landuyt W, Nuyts S, Van Mellaert L, van Oosterom A, Lambin P, Anne J (2001a) Specific targeting of cytosine deaminase to solid tumors by engineered Clostridium acetobutylicum. Cancer Gene Ther 8: $294-297$

Williams DR, Young DI, Young M (1990) Conjugative plasmid transfer from Escherichia coli to Clostridium acetobutylicum. J Gen Microbiol 136: 819-826

Wilson WR, Pullen SM, Hogg A, Helsby NA, Hicks KO, Denny WA (2002) Quantitation of bystander effects in nitroreductase suicide gene therapy using three-dimensional cell cultures. Cancer Res 62: $1425-1432$

Workman P, Twentyman P, Balkwill F, Balmain A, Chaplin D, Double J, Embleton J, Newell D, Raymond R, Stables J, Stephens T, Wallace J (1998) United Kingdom Co-ordinating Committee on Cancer research (UKCCR) guidelines for welfare of animals in experimental neoplasia [second edition]. Br J Cancer 77: 1-10 